\title{
Preparation and characterization of modified sepiolite for the removal of Acid green 20 from aqueous solutions: isotherm, kinetic and process optimization
}

\author{
Mohammad Malakootian $^{1,2} \cdot$ Hiwa Hossaini ${ }^{3,4} \cdot$ Ali Asadipour $^{5} \cdot$ Mozhgan Daneshkhah $^{6}$
}

Received: 21 November 2017 / Accepted: 11 September 2018 / Published online: 24 September 2018

(c) The Author(s) 2018

\begin{abstract}
In this study, adsorption of Acid green $20\left(\mathrm{AG}_{20}\right)$ by modified sepiolite, hexadecyltrimethylammonium-modified sepiolite (HDTMA-Sep), was optimized using response surface methodology based on a central composite design. Characteristics of natural sepiolite and modified sepiolite can be analyzed by FTIR and XRD techniques. In order to achieve a better comprehension of applicability of adsorbent for removing dyes from colored effluents, isotherm and kinetic studies were also carried out. The maximum dye removal of $78 \%$ and $72 \%$ for synthetic solutions and real wastewater, respectively, was obtained at the initial dye concentration of $77.1 \mathrm{mg} / \mathrm{L}$, contact time of $24.81 \mathrm{~min}$, solution $\mathrm{pH}$ of 6.19 and adsorbent dosage of $1.03 \mathrm{~g} / \mathrm{L}$. The kinetic studies revealed that the adsorption process followed pseudo-second-order model. The adsorption data were best fitted to Freundlich model. The result indicated that the contact time and dye concentration have more influence on the removal efficiency rather than $\mathrm{pH}$ and amount of adsorbent. The experimental data from this study indicated that the modified sepiolite is an efficient adsorbent for dye removal from aqueous solutions.
\end{abstract}

Keywords Adsorption $\cdot$ Sepiolite $\cdot$ Response surface methodology $\cdot$ Acid green $20 \cdot$ Central composite design

Mozhgan Daneshkhah

m.daanesh2010@gmail.com

1 Environmental Health Engineering Research Center, Kerman University of Medical Sciences, Kerman, Iran

2 Department of Environmental Health, School of Public Health, Kerman University of Medical Sciences, Kerman, Iran

3 Department Of Environmental Health Engineering, School of Public Health, Kermanshah University of Medical Sciences, Kermanshah, Iran

4 Research Center for Environmental Determinants of Health (RCEDH), Kermanshah University of Medical Sciences, Kermanshah, Iran

5 Department of Medicinal Chemistry, Pharmaceutical Research Center, School of Pharmacy, Kerman University of Medical Sciences, Kerman, Iran

6 Environmental Health Engineering, Department of Environmental Health, School of Public Health, Kerman University of Medical Sciences, Kerman, Iran

\section{Introduction}

Dyes are used in various industrials such as textile, tannery, paper, printing, pharmaceutical and plastic (Wang et al. 2015a; Shirsath et al. 2013). These materials are considered as important and harmful pollutants in industrial effluents. Dyes are categorized in different ways including their applications and structures (dos Santos et al. 2007).

Azo dyes are a group of dyes with one or more azo bonds $(-\mathrm{N}=\mathrm{N}-)$ in their structures which are estimated around $60-70 \%$ of all textile used dyes (Thiam et al. 2015; Olya et al. 2015; Dasgupta et al. 2015). Due to their strong stability and high water solubility, treatment of wastewater containing azo dyes is difficult (Dasgupta et al. 2015). Some problems including resistance to aerobic degradation, generation of toxic aromatic amines under anoxic conditions and generation of carcinogenic and mutagenic activities have been reported (Tee et al. 2015; Wang et al. 2015a; Jin et al. 2014; Fan et al. 2015). Therefore, in order to protect the environment and human health, decolorization of these effluents should be considered.

Acid green $20\left(\mathrm{AG}_{20}\right)$ was selected as the non-biodegradable model of azo dyes (Zhang and Zheng 2009). Many 
industries including textile and printing use these dyes in their processes because of light resistance ability, perspiration and wash ability (Zhang and Zheng 2009).

Several techniques including coagulation, ion exchange, filtration, biological treatment, advanced oxidation processes, electrolysis, activated sludge, adsorption and solvent extraction have been proposed to remove dyes from the industrial wastewater (Tee et al. 2015; Zhang et al. 2015; Jin et al. 2014). Due to their chemical structure and potentially carcinogenic effects, conventional physical and chemical methods are not able to remove completely this dye from effluents (Zhou et al. 2012). Among these techniques, adsorption is proven to be effective and economical method for dyes removal from industrial wastewater (Wang et al. 2015a; Elwakeel et al. 2017a, b; Malakootian et al. 2017). Studies showed that several materials, including chitosan (Crini and Badot 2008), fly ash (Mall et al. 2006), activated carbon (Cheng et al. 2015) and natural clays such as bentonite (Tahir and Rauf 2006), montmorillonite (Wang et al. 2004), sepiolite (Doğan et al. 2007) and zeolite (Jin et al. 2014), could be used as an effective adsorbent for the removal of dyes from wastewaters.

Sepiolite (hydrous magnesium silicate) is a zeolite-like clay material with $\mathrm{Si}_{12} \mathrm{O}_{30} \mathrm{Mg}_{8}(\mathrm{OH})_{4}\left(\mathrm{H}_{2} \mathrm{O}\right)_{4} 8 \mathrm{H}_{2} \mathrm{O}$ formula and characterized by its fibrous morphology that is due to its crystalline structure (Qiu et al. 2013; Marjanović et al. 2013). It presents a structure of needlelike particles which can be explained as composition of talc-like sheets that is made of two sheets of tetrahedral silica and a central octahedral magnesium sheet (Lescano et al. 2014; Lazarević et al. 2012). Because of sorptive, rheological and catalytic properties, this material is extensively used in various industrial applications (Fu et al. 2015; Algoufi et al. 2014). Sepiolite has a higher surface area $\left(\sim 300 \mathrm{~m}^{2} / \mathrm{g}\right)$ (Algoufi et al. 2014) than other clay minerals such as $\mathrm{Hj}$ clay (Li et al. 2016), Fesmectite (Li et al. 2015), kaolinite (Üzum et al. 2009) and montmorillonite (Bhowmick et al. 2014).

In addition, sepiolite has low price and produced in large amount (Chao and Chen 2012). Generally, negative surface clay minerals showed little success to adsorb anionic pollutants especially acidic dyes (Jin et al. 2014). Several methods can be used to alter the properties of sepiolite surface (Gök et al. 2008; Özcan et al. 2006; Wang et al. 2012; Lazarević et al. 2007): modification by the use of surfactant through simple ion-exchange reaction to direct van der Waals interaction between adsorbate and organic surfactant cations is one of them. The surfactant-modified clay entitled "organoclay," surfactant modification strongly enhanced the transformation of organophobic compound toward organophilic surface, and finally, the adsorption capacity increases ( $\mathrm{Li}$ and Bowman 2001). In the previous study, hexadecyltrimethylammonium bromide (HDTMA-Br) was used to enhance adsorption capacity related to nitrate, chromate and arsenate ( $\mathrm{Li}$ and Bowman 2001). Hexadecyltrimethylammonium (HDTMA$\mathrm{Br}$ ) bromide, a cationic surfactants with tetra-substituted ammonium with permanently charged quaternary nitrogen and a long straight alkyl $\left(\mathrm{C}_{16}\right)$ chain that make unique with a high degree of hydrophobicity, is a good candidate for sepiolite modification (Kaboorani and Riedl 2015). HDTMA has good points such as availability, low cost and possibility to be degraded by some microorganism in the environment (Kaboorani and Riedl 2015). Malakootian et al. conducted studies on the removal dyes from aqueous solutions (Malakootian et al. 2015; Malakootian 2016; Malakootian et al. 2013, 2016).

Response surface methodology (RSM) as a reliable statistical method applied to evaluate the interaction effects among parameters with least number of experimental runs (Yolmeh et al. 2014). Thus in this study, RSM based on central composite design (CCD) was used for optimization and estimation of the adsorption process using modified sepiolite to develop a mathematical correlation between the selected parameters including adsorbent dosage, initial dye concentration, contact time and solution $\mathrm{pH}$ in $\mathrm{AG}_{20}$ removal from aqueous solution and real wastewater.

\section{Experimental}

\section{Chemicals}

The Acid green $20\left(\mathrm{AG}_{20}\right)$ with purity of $>87 \%$ was purchased from Alvan Sabet Company, Iran. The main properties of $A_{20}$ are shown in Table 1. Sepiolite (Sep) was

Table 1 The main properties of AG 20 (Zhang and Zheng 2009)

Name Acid green $20\left(\mathrm{AG}_{20}\right) \quad$ Molecular formula


prepared from Dorkav Mining Company, Iran. The chemical composition of sepiolite (\%) was: $\mathrm{SiO}_{2}, 55.52 ; \mathrm{Al}_{2} \mathrm{O}_{3}$, $0.4 ; \mathrm{Fe}_{2} \mathrm{O}_{3}, 0.68 ; \mathrm{MgO}, 16.29 ; \mathrm{CaO}, 1.3 ; \mathrm{Na}_{2} \mathrm{O}, 0.02 ; \mathrm{K}_{2} \mathrm{O}$, 0.01; and $\mathrm{TiO}_{2}, 0.02$. Also, sepiolite has a specific surface area: $179.9 \mathrm{~m}^{2} / \mathrm{g}$; pore size: $15-40 \mathrm{~nm}$ and pore volume: $0.378 \mathrm{~cm}^{3} / \mathrm{g}$ (Sharifipour et al. 2015). Hexadecyltrimethylammonium bromide, sodium hydroxide and sulfuric acid were purchased from Merck, Germany. All other chemicals used in this experiments were of analytical grade and used without further purification.

\section{Preparation and characterization of adsorbent (HDTMA-Sep)}

Four grams of sepiolite (60-mesh sieve) was added into $100 \mathrm{~mL}$ HDTMA solution with the concentration of $2 \%$ (wt/wt) and thoroughly shaked at $200 \mathrm{rpm}$ for $48 \mathrm{~h}$, after that the suspension was centrifuged (Hettich, EBA 20, Germany) and the supernatant was separated. In order to remove excess HDTMA, the centrifuged solid was soaked several times in distilled water, and then, the HDTMA-Sep was dried in an oven (UNB-400, Germany) at $120{ }^{\circ} \mathrm{C}$ for $6 \mathrm{~h}$. The dried powder was sieved through a 60 mesh. Finally, white powder (HDTMA-Sep) stored in a desiccator until use (Jin et al. 2014).

Functional groups in natural sepiolite (N-Sep) and HDTMA-Sep were determined with Fourier transform infrared spectroscopy (Tensor 27, Bruker, Germany) in the range $4000-400 \mathrm{~cm}^{-1}$. X-ray diffractometer (XPERT, Holland) working at $30 \mathrm{~mA}$ and $40 \mathrm{kV}$ using $\mathrm{Cu} \mathrm{K} \alpha$ radiation source $(\lambda=1.5418 \AA)$ at $2 \Theta=2-70^{\circ}$ with counting time of $1.5 \mathrm{~s}$ and step size of 0.02 was used to analyze the crystalline phase of natural sepiolite.

\section{Adsorption experiments}

Batch adsorption experiments were conducted in various initial concentrations of dye, adsorbent dosage, different contact times and solution $\mathrm{pH}_{\mathrm{s}}$, which at first designed with response surface methodology. $\mathrm{AG}_{20}$ stock solution was prepared by dissolving $\mathrm{AG}_{20}$ into deionized water, and different concentrations of $\mathrm{AG}_{20}$ solution were prepared by proper dilution of $\mathrm{AG}_{20}$ stock solution. The $\mathrm{pH}$ values of samples were adjusted with $\mathrm{NaOH}$ or $\mathrm{H}_{2} \mathrm{SO}_{4}(0.1 \mathrm{~N})$. All experiments were done in $100-\mathrm{mL}$ beaker containing $50 \mathrm{~mL}$ dye solution and shaked at $200 \mathrm{rpm}$ during contact time using mechanical shaker. Suspension was centrifuged at $3700 \mathrm{rpm}$ for $10 \mathrm{~min}$, and then, liquid phase was separated by $0.45-\mu \mathrm{m}$ filter. The final $\mathrm{AG}_{20}$ concentration was determined by UV-Vis spectrophotometer (Shimadzu, UV-1800, Japan) at wavelength of $606 \mathrm{~nm}$, and according to Eqs. 1 and 2, the removal efficiency $(\%)$ and adsorption capacity $\left(q_{\mathrm{e}}\right)$, respectively, were calculated:
$\operatorname{Removal}_{\text {efficiency }}(\%)=\left(\frac{C_{0}-C_{t}}{C_{0}}\right) \times 100$

$q_{\mathrm{e}}=\left(\frac{C_{0}-C_{e}}{m}\right) \times V$

where $C_{0}(\mathrm{mg} / \mathrm{L})$ and $C_{e}(\mathrm{mg} / \mathrm{L})$ are initial and equilibrium concentrations of $\mathrm{AG}_{20}$ in the solution, respectively, and $C_{t}$ $(\mathrm{mg} / \mathrm{L})$ is the concentration of $\mathrm{AG}_{20}$ at time of $\mathrm{t}(\mathrm{min}) . V$ (L) is the volume of $\mathrm{AG}_{20}$ solution, and $m$ is the mass of the adsorbent in grams.

To ensure the accuracy of the result, all experiments were duplicated and mean of values was considered for analysis of the data.

\section{Response surface methodology (RSM)}

The experimental design was done based on CCD in software Design-Expert V. 7. 0. 0. Response surface methodology (RSM) is a statistical method that is applied to improve, develop and optimize chemical process (Ye et al. 2016). The main objective of RSM is to optimize the response which is influenced by various independent input parameters (Mandal et al. 2015). RSM based on central composite design (CCD) was used for optimization of $\mathrm{AG}_{20}$ decolorization process. Application of CCD allows estimation of four independent parameters effectiveness, including the initial $\mathrm{AG}_{20}$ concentration, solution $\mathrm{pH}$, adsorbent dosage and contact time on removal percentage. The previous studies have stated that the concentration range of dyes in textile industry wastewater varies between 10 and $200 \mathrm{mg} / \mathrm{L}$ (El Haddad et al. 2014). Thus, $\mathrm{AG}_{20}$ concentration of solutions was selected in the range of 10-100 $\mathrm{mg} / \mathrm{L}$. In this model, the number of experimental runs was calculated from Eq. 3 (Srivastava et al. 2015):

$N=2^{n}+2 n+x_{c}$

where $N, n$ and $X_{c}$ are the number of experimental runs, the number of variables and the number of central points, respectively.

According to Eq. 3, based on 4 variables and 6 central points, 30 runs were acquired. Five levels of $-\alpha,-1,0,+1$ and $+\alpha$ were coded for each variation. On the basis of program setting, the " $\alpha$ value" was coded as 2 . In Table 2 , the operational ranges of the input variables as coded level and actual units of measurements are shown.

The quadratic equation for predicting the optimal conditions with RSM based on CCD is shown in Eq. 4 (Azizi et al. 2012; Karimifard and Moghaddam 2016):

$Y=\beta_{0}+\sum_{i=1}^{n} \beta_{i} \chi_{i}+\sum_{i=1}^{n} \beta_{i i} \chi_{i}^{2}+\sum_{i=1}^{n-1} \sum_{j=i+1}^{n} \beta_{i j} \chi_{i} \chi_{j}$ 
Table 2 Operational range of input variables as coded level and actual units for the adsorption of $\mathrm{AG}_{20}$ onto HDTMA-Sep

\begin{tabular}{lllllrrr}
\hline No. & Code & Parameters & \multicolumn{2}{l}{ Parameters level } \\
\cline { 3 - 7 } & & & $-2(\alpha)$ & -1 & 0 & +1 & $+2(\alpha)$ \\
\hline 1 & A & Contact time (min) & 5 & 28.75 & 52.5 & 76.25 & 100 \\
2 & B & Adsorbent dosage (g/L) & 0.5 & 0.88 & 1.25 & 1.63 & 2 \\
3 & C & Dye concentration (mg/L) & 10 & 32.5 & 55 & 77.5 & 100 \\
4 & D & Solution $\mathrm{pH}$ & 3 & 4.5 & 6 & 7.5 & 9 \\
\hline
\end{tabular}

where $Y$ indicates the corresponding response of input variables $\beta_{0}, \beta_{i}, \beta_{i j}$ and $\beta_{i i}$ symbolizing the constant, the linear, interaction and quadratic regression coefficients, respectively, and $X_{i}$ and $X_{j}$ are value of coded independent variables. The validity of the model fitness and significance analysis of variables was evaluated by means of ANOVA.

\section{Kinetic studies}

In this study, experimental data were modeled by the pseudo-first-order and pseudo-second-order model equation. The pseudo-first-order model presumes that the rate of change of the solute adsorption for the whole range of contact time may cause to change in the adsorption capacity (Eq. 5) (Wang et al. 2015b; Kumar and Tamilarasan 2013):

$\log \left(q_{e}-q_{t}\right)=\log q_{e}-\frac{K_{1}}{2.303} t$

where $K_{1}(1 / \mathrm{min})$ is adsorption rate constant of the pseudofirst order, $q_{e}(\mathrm{mg} / \mathrm{g})$ is the amount of adsorbed $\mathrm{AG}_{20}$ at equilibrium and $q_{t}(\mathrm{mg} / \mathrm{g})$ is the amount of $\mathrm{AG}_{20}$ adsorbed on at any time.

Pseudo-second-order model supposed that the rate-limiting step includes resembles over in the whole adsorption processes and chemical forces of attraction. Equation 6 shows the linear form of the pseudo-second-order model (Kumar and Tamilarasan 2013; Wang et al. 2015b):

$\frac{t}{q}=\frac{1}{K_{2} q_{e}^{2}}+\frac{1}{q_{e}} t$

where $K_{2}(\mathrm{~g} / \mathrm{mg} \mathrm{min})$ is adsorption rate constant of the pseudo-second-order equation and $q_{e}(\mathrm{mg} / \mathrm{g})$ is the amount of adsorbed $\mathrm{AG}_{20}$ at equilibrium.

\section{Adsorption isotherm studies}

Isotherm study was conducted to clarify the distribution behavior of dye between solid and liquid phases at constant temperature and equilibrium. In this study, two isotherm models, Freundlich and Langmuir, were used. The Freundlich isotherm is applied based on the hypothesis that the sorption process was comprised of a heterogeneously layer.
Freundlich equation (Eq. 7) in the linearized form is (AnariAnaraki and Nezamzadeh-Ejhieh 2015):

$\log q_{e}=\log k_{f}+\frac{1}{n_{f}} \log C_{e}$

where $q_{e}(\mathrm{mg} / \mathrm{g})$ is the equilibrium capacity, $C_{e}(\mathrm{mg} / \mathrm{L})$ is an equilibrium concentration of the adsorbate in liquid phase, $K_{f}\left((\mathrm{mg} / \mathrm{g})(\mathrm{L} / \mathrm{mg})^{1 / n}\right)$ is a constant associated related to the adsorption capacity of the adsorbent and $1 / n$ is intensity of adsorption.

Value of $1 / n$ between 0 and 1 verified the adsorption intensity or surface heterogeneity and values lower than 1 show a normal Freundlich isotherm, while values higher than one show cooperative adsorption (Ghaedi and Kokhdan 2015).

The Langmuir isotherm proposes that the adsorption continues in a monolayer onto homogeneous surface. Langmuir equation (Eq. 8) in the linearized form is as follows (Kumar and Tamilarasan 2013):

$\frac{C_{e}}{q_{e}}=\frac{C_{e}}{q_{m}}+\frac{1}{K_{l} q_{m}}$

where $q_{e}(\mathrm{mg} / \mathrm{g})$ and $C_{e}(\mathrm{mg} / \mathrm{L})$ are the equilibrium capacity and concentration, respectively. $q_{m}(\mathrm{mg} / \mathrm{g})$ is the maximum quantity of adsorbed dye per unit mass of sorbent at complete monolayer on the surface bound, and $K_{L}(\mathrm{~L} / \mathrm{mg})$ is a constant associated with the attraction of the binding sites.

\section{Results and discussion}

\section{FTIR analysis}

Functionality present at the adsorbent surface was detected by FTIR spectra between 4000 and $400 \mathrm{~cm}^{-1}$. The variation of functional groups is shown in Fig. 1. The band at $3686.56 \mathrm{~cm}^{-1}$ that assigns to stretching $(\mathrm{vOH})$ vibration of hydroxyl group (belong to $\mathrm{Mg}_{3} \mathrm{OH}$ ) attached to octahedral $\mathrm{Mg}$ ions placed in the inner blocks of N-Sep and HDTMASep (Bakhtiary et al. 2013). The broadband at $3435.51 \mathrm{~cm}^{-1}$ attributed to $\mathrm{H}_{2} \mathrm{O}$ was observed at bare and treated sepiolite (Madejová 2003). The spectrum of HDMTA-Sep shows a pair of bands at 2857.21 and $2928.37 \mathrm{~cm}^{-1}$. These two 


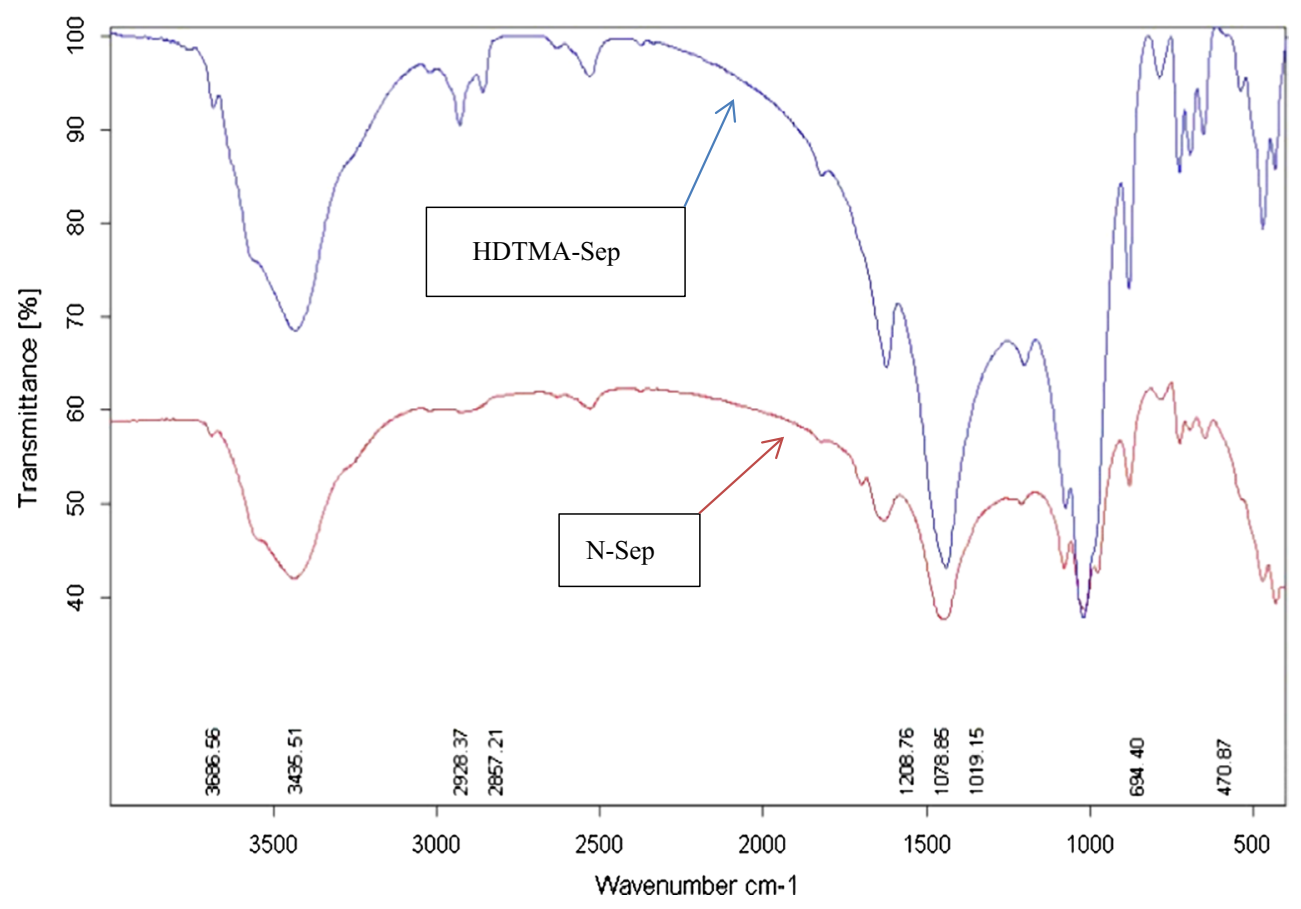

Fig. 1 FTIR spectra of N-Sep and HDTMA-Sep

bands were assigned to the symmetrical and asymmetrical $\mathrm{CH}_{2}$-stretching vibration (Rožić and Miljanić 2011). The observed bands at about 1208.76 and $1078.85 \mathrm{~cm}^{-1}$ are attributed to the $\mathrm{Si}-\mathrm{O}$ vibrations (Xu and Boyd 1995). The deep band at $1019.15 \mathrm{~cm}^{-1}$ shows the stretching of $\mathrm{Si}-\mathrm{O}$ in the $\mathrm{Si}-\mathrm{O}-\mathrm{Si}$ group of the tetrahedral sheet ( $\mathrm{Li}$ and Bowman 1997). The observed peak at $694.40 \mathrm{~cm}^{-1}$ corresponds to the bending vibration of $\mathrm{Mg}_{3} \mathrm{OH}$ for bare and treated sepiolite (Xu and Boyd 1995). The band at $470.87 \mathrm{~cm}^{-1}$ assigned to Si-O-Si bending vibration of both sepiolite (Rožić and Miljanić 2011; Li and Bowman 1997). As shown in Fig. 1, no real shift occurred in observed peaks, but their intensity was dramatically changed after HDTMA treatment.

\section{XRD analysis}

The X-ray diffractogram is depicted in Fig. 2. The diffractogram showing a sharp reflection peak at $2 \Theta=7.223$ $(12.1 \AA$ ) is a sepiolite characteristic peak (Li and Bowman 1997; Bakhtiary et al. 2013). According to the studies of Bakhtiary et al. (2013) (Bakhtiary et al. 2013), Liu et al. (2014)(Liu et al. 2014), Gajowiak et al. (2013) (Gajowiak
Fig. 2 X-ray diffraction of $\mathrm{N}-\mathrm{Sep}$

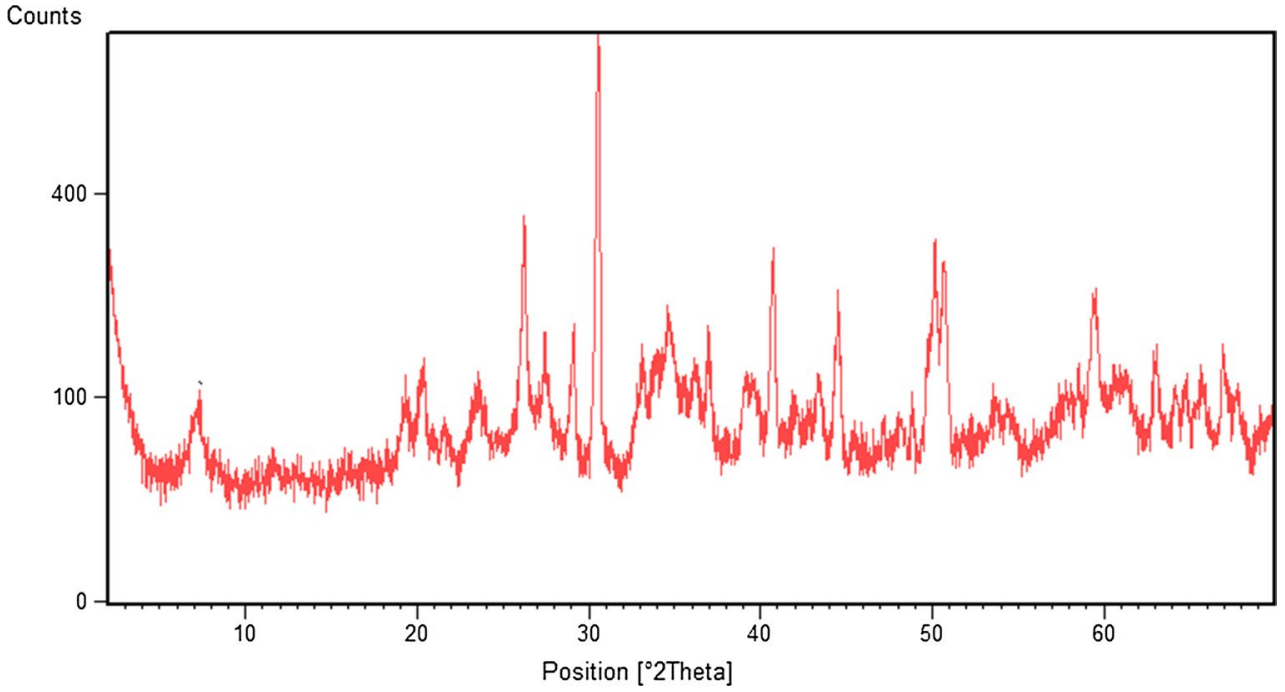


et al. 2013) and Ozcan and Gok (2012) (Özcan and Gök 2012), structure of the modified clay with cationic surfactants does not have considerable difference with the bare one. It can be concluded that $\mathrm{HDTM}^{+}$cations attach to the edge of sepiolite and cannot enter the internal pores of sepiolite.

\section{Finding of CCD}

An empirical relationship in terms of coded factors from RSM based on CCD obtained for $\mathrm{AG}_{20}$ removal based on quadratic model is shown in Eq. 9:

Removal $=78.50+2.65 A+1.33 B+1.97 C+0.6 D$

$$
-0.77 B C-0.79 C D-3.13 A^{2}-1.30 B^{2}-2.50 C^{2}
$$

Based on this equation, the effects of each factor and their interaction on the response can be understood. The positive and negative signs in this equation are used to indicate synergistic and antagonistic effects, respectively. The experimental design and $\mathrm{AG}_{20}$ removal percentage are shown in Table 3.

The statistical adequacy of the model is tested using analysis of variance (ANOVA). ANOVA is a statistical method which applied to subdivide the whole variation in a set of data into constituent parts related to particular sources of variation for the aim of testing hypothesis about the parameters of the model (Subramaniam and Ponnusamy 2015).

Table 4 shows the regression parameters of ANOVA for the predicted quadratic model. The $F$ value of 50.24 and $P$ value of regression less than 0.05 implied that the model is statistically significant. Also, $R$-squared $\left(R^{2}\right)$ for the quadratic model was 0.9832 .

The $P$ value of lack of fit $(0.5997)$ is more than 0.05 which demonstrates that lack of fit was not significant and the model was significant. The value of "Adequate precision" more than $4(>4)$ is favor (Ezechi et al. 2015; Zinatizadeh et al. 2006), and for the present study, the value of 23.960 was obtained as "Adequate precision" which is preferred.

According to the above-mentioned reasons obtained from ANOVA, the quadratic model is statistically significant and can explain the relationship between the response and variable adequately.

Based on Table 4 and consideration of two columns "Source" and "Sum of square," Fig. 3 is designed. In this Fig. 3, the percent of contribution off our parameters including A (contact time), B (adsorbent dosage), C (dye concentration) and $\mathrm{D}(\mathrm{pH})$ in the dye removal efficiency is shown. According to this figure, among these parameters, A and C have more influence on the removal efficiency rather than other two parameters (B and D).
Table 3 Experimental design and dye removal percentage through the adsorption $\mathrm{AG}_{20}$ onto HDTMA-Sep

\begin{tabular}{|c|c|c|c|c|c|}
\hline Run & A & B & $\mathrm{C}$ & $\mathrm{D}$ & Removal\% \\
\hline 1 & 52.50 & 1.25 & 55.00 & 6.00 & 80 \\
\hline 2 & 76.25 & 1.63 & 77.50 & 4.50 & 79 \\
\hline 3 & 100 & 1.25 & 55.00 & 6.00 & 70 \\
\hline 4 & 28.75 & 0.88 & 32.50 & 7.50 & 67 \\
\hline 5 & 28.75 & 1.63 & 77.50 & 4.50 & 70 \\
\hline 6 & 28.75 & 1.63 & 32.50 & 4.50 & 67 \\
\hline 7 & 28.75 & 1.63 & 77.50 & 7.50 & 70 \\
\hline 8 & 52.50 & 1.25 & 55.00 & 6.00 & 79 \\
\hline 9 & 76.25 & 1.63 & 32.50 & 4.50 & 73 \\
\hline 10 & 28.75 & 0.88 & 77.50 & 4.50 & 70 \\
\hline 11 & 52.50 & 1.25 & 55.00 & 6.00 & 77 \\
\hline 12 & 28.75 & 1.63 & 32.50 & 7.50 & 70 \\
\hline 13 & 52.50 & 1.25 & 55.00 & 6.00 & 79 \\
\hline 14 & 52.50 & 2.00 & 55.00 & 6.00 & 76 \\
\hline 15 & 52.50 & 1.25 & 55.00 & 9.00 & 75 \\
\hline 16 & 52.50 & 1.25 & 55.00 & 6.00 & 78 \\
\hline 17 & 28.75 & 0.88 & 77.50 & 7.50 & 70 \\
\hline 18 & 52.50 & 0.50 & 55.00 & 6.00 & 73 \\
\hline 19 & 76.25 & 1.63 & 32.50 & 7.50 & 76 \\
\hline 20 & 76.25 & 0.88 & 77.50 & 4.50 & 76 \\
\hline 21 & 52.50 & 1.25 & 10.00 & 6.00 & 65 \\
\hline 22 & 28.75 & 0.88 & 32.50 & 4.50 & 64 \\
\hline 23 & 52.50 & 1.25 & 55.00 & 3.00 & 77 \\
\hline 24 & 76.25 & 0.88 & 32.50 & 4.50 & 68 \\
\hline 25 & 76.25 & 0.88 & 32.50 & 7.50 & 75 \\
\hline 26 & 52.50 & 1.25 & 55.00 & 6.00 & 78 \\
\hline 27 & 5.00 & 1.25 & 55.00 & 6.00 & 62 \\
\hline 28 & 76.25 & 1.63 & 77.50 & 7.50 & 77.5 \\
\hline 29 & 52.50 & 1.25 & 100 & 6.00 & 72 \\
\hline 30 & 76.25 & 0.88 & 77.50 & 7.50 & 76 \\
\hline
\end{tabular}

$A=$ time $(\min ) ; B=\mathrm{M}(\mathrm{g} / \mathrm{L}) ; C=C(\mathrm{mg} / \mathrm{L}) ; D=\mathrm{pH}$

\section{Optimized values of parameters}

The primary objective of the present study was the determination of the optimum condition for examined parameters, including the initial $\mathrm{AG}_{20}$ concentration, contact time, $\mathrm{pH}$ of the solution and adsorbent dosage. The optimal condition was acquired at the initial $\mathrm{AG}_{20}$ concentration of $77.1 \mathrm{mg} / \mathrm{L}$, contact time of $24.81 \mathrm{~min}, \mathrm{pH}$ of 6.19 and adsorbent dosage of $1.03 \mathrm{~g} / \mathrm{L}$ with the predicted removal efficiency of 78 . The verification experiment was resulted in the removal efficiency of 78.5 which is in agreement with predicted result. Also, the $\mathrm{AG}_{20}$ adsorption capacity at optimum conditions obtained $58 \mathrm{mg} \mathrm{AG}_{20}$ per gram of modified sepiolite. Similar result has been reported by Marjanovic et al. (2013) in the case of chromium (VI) adsorption onto functionalized acidactivated sepiolite (Marjanovic et al. 2013). By comparison, 
Table 4 ANOVA result for quadratic model terms

\begin{tabular}{lcrrrrr}
\hline Source & \multicolumn{1}{c}{ SS } & DF & \multicolumn{1}{c}{ MS } & $F$ value & $P$ value & \\
\hline Model & 700.55 & 14 & 50.04 & 50.24 & $<0.0001$ & Significant \\
A-time & 151.30 & 1 & 151.30 & 151.91 & $<0.0001$ & \\
B-M & 25.41 & 1 & 25.41 & 25.52 & 0.0003 & \\
C-C & 83.39 & 1 & 83.39 & 83.72 & $<0.0001$ & \\
D-pH & 5.19 & 1 & 5.19 & 5.21 & 0.0414 & \\
AB & 4.59 & 1 & 4.59 & 4.61 & 0.0530 & \\
AC & 4.59 & 1 & 4.59 & 4.61 & 0.0530 & \\
AD & 0.28 & 1 & 0.28 & 0.28 & 0.6059 & \\
BC & 8.03 & 1 & 8.03 & 8.06 & 0.0149 & \\
BD & 0.026 & 1 & 0.026 & 0.027 & 0.8732 & \\
CD & 8.58 & 1 & 8.58 & 8.61 & 0.0125 & \\
A $^{2}$ & 256.25 & 1 & 256.25 & 257.28 & $<0.0001$ & \\
B $^{2}$ & 24.25 & 1 & 24.25 & 24.35 & 0.0003 & \\
C $^{2}$ & 164.09 & 1 & 164.09 & 164.75 & 0.0001 & \\
$\mathrm{D}^{2}$ & 0.093 & 1 & 0.093 & 0.093 & 0.7654 & \\
Residual & 11.59 & 12 & 1 & & & \\
Lack of fit & 6.45 & 7 & 0.92 & 0.84 & 0.5997 & \\
Pure error & 5.50 & 5 & 1.1 & & & \\
Core total & 712.50 & 26 & & & \\
\hline
\end{tabular}

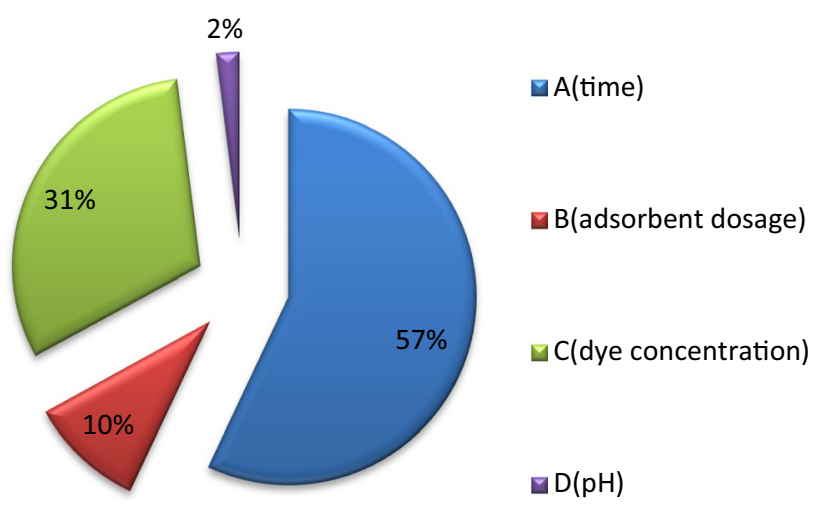

Fig. 3 Contribution percentage of parameters in removal efficiency

the adsorption capacity of modified sepiolite $(58 \mathrm{mg} / \mathrm{g}$ ) was higher than the adsorption capacity of HDTMA-coated zeolite $(38.96 \mathrm{mg} / \mathrm{g})$ (Jin et al. 2014) and calcium-rich sepiolite (32 mg/g) (Yin et al. 2011). Thereby, it can be stated that HDTMA-Sep is an efficient adsorbent for the removal of $\mathrm{AG}_{20}$.

In order to assess the applicability of HDTMA-Sep for the removal of $\mathrm{AG}_{20}$ from real wastewater, an experiment under optimal condition with spiked amount of $77 \mathrm{mg} / \mathrm{L}$ of $\mathrm{AG}_{20}$ was conducted on textile wastewater. The main characteristics of the used wastewater are shown in Table 5. The results showed that HDTMA-Sep has a great tendency toward dye and the removal efficiency of 72 was obtained. Little difference between the removal efficiency in aqueous solution and real wastewater showed good tendency of modified sepiolite
Table 5 Main parameters of textile wastewater

\begin{tabular}{llr}
\hline Wastewater & Unit & Value \\
\hline $\mathrm{AG}_{20}$ & $\mathrm{mg} / \mathrm{L}$ & 77 \\
$\mathrm{pH}$ & - & 10 \\
Temperature & ${ }^{\circ} \mathrm{C}$ & 21 \\
Turbidity & $\mathrm{NTU}$ & 640 \\
$\mathrm{EC}$ & $\mu \mathrm{S} / \mathrm{cm}$ & 4840 \\
$\mathrm{COD}$ & $\mathrm{mg} / \mathrm{L}$ & 1600 \\
\hline
\end{tabular}

toward dyes even in the presence of organic and inorganic matter that exist in real wastewater.

\section{Kinetic studies}

The kinetics studies were done at optimum condition including various concentrations of $\mathrm{AG}_{20}(10-100 \mathrm{mg} / \mathrm{L})$, $\mathrm{pH}$ : 6.19 , adsorbent dosage of $1.03 \mathrm{~g} / \mathrm{L}$ and contact time equal to $24.81 \mathrm{~min}$. The plots of kinetic studies are presented in Fig. 4. The kinetic parameters are shown in Table 6. According to this table, pseudo-second-order kinetic model has the higher determination coefficient in comparison with the pseudo-first-order kinetic model $\left(R^{2}=0.9284\right)$, which showed that adsorption process was controlled by chemisorption (Zheng et al. 2015; Zhu et al. 2013). So the adsorption ${A G_{20}}_{20}$ onto HDTMA-Sep follows pseudo-second-order kinetic model. The results of Ozcan (Özcan et al. 2006), Jin et al. (Jin et al. 2014) and Zheng et al. (Zheng et al. 2015) were in agreement with the finding of this study. By comparison, the rate constant 
a

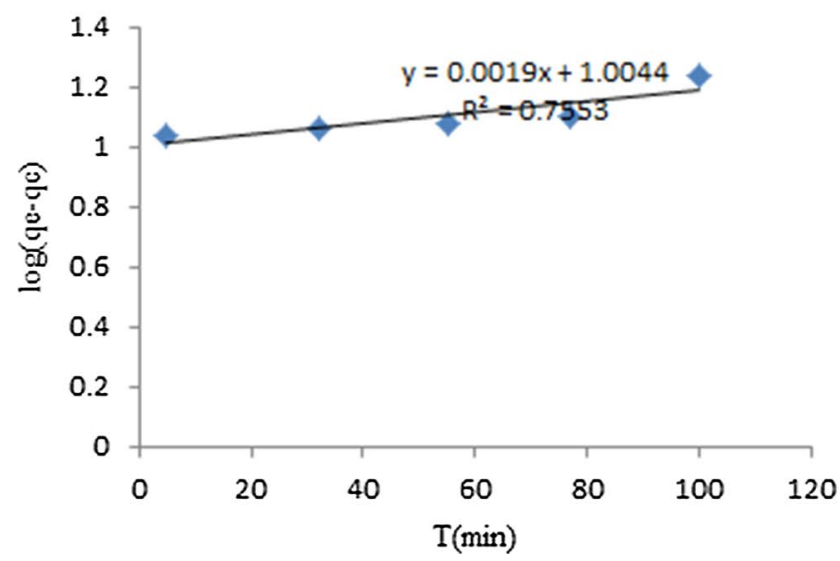

b

pseudo - second order model

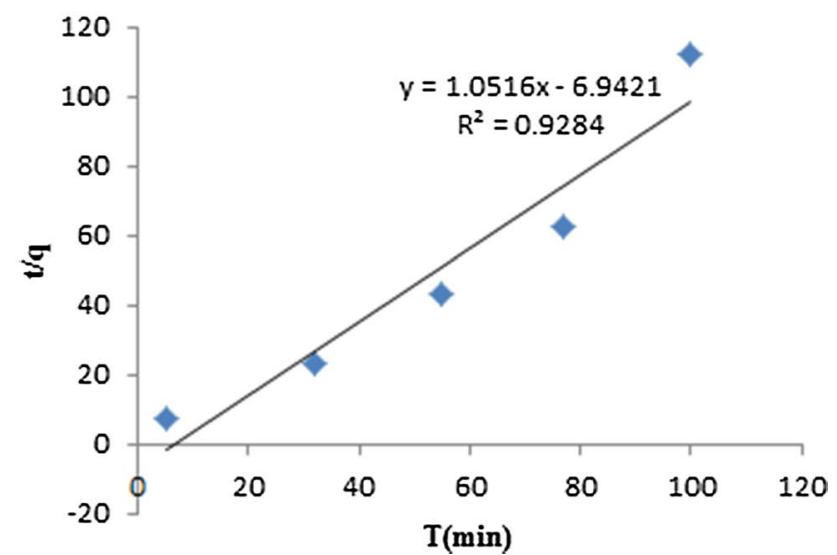

Fig. 4 The plots of pseudo-first-order model (a) and pseudo-second-order model (b)

Table 6 Result of $\mathrm{AG}_{20}$ kinetic onto HDTMA-Sep

\begin{tabular}{lll}
\hline Model & Parameter & Value \\
\hline Pseudo-first-order & $\mathrm{K}_{1}\left(\mathrm{~min}^{-1}\right)$ & 0.005 \\
& $\mathrm{q}_{\mathrm{e}}(\mathrm{mg} / \mathrm{g})$ & 0.10 \\
& $R^{2}$ & 0.7553 \\
Pseudo-second-order & $\mathrm{K}_{2}(\mathrm{~g} / \mathrm{mg} \cdot \mathrm{min})$ & 0.15 \\
& $\mathrm{q}_{\mathrm{e}}(\mathrm{mg} / \mathrm{g})$ & 0.95 \\
& $R^{2}$ & 0.9284 \\
\hline
\end{tabular}

of pseudo-second order of modified sepiolite $(0.15 \mathrm{~g} /$ mg min) was better than the constant rate of HDTMA-zeolite $\left(5.5 \times 10^{-3} \mathrm{~g} / \mathrm{mg} \mathrm{min}\right)$ (Jin et al. 2014), DTMA-bentonite $\left(6.32 \times 10^{-4} \mathrm{~g} / \mathrm{mg} \mathrm{min}\right)$ (Özcan et al. 2004) and DTMA-sepiolite $\left(1.23 \times 10^{-1} \mathrm{~g} / \mathrm{mg}\right.$ min) (Gök et al. 2008).

\section{Adsorption isotherm studies}

The adsorption isotherm studies were conducted in different concentrations of HDTMA-Sep $(0.5-2 \mathrm{~g} / \mathrm{L})$, solution $\mathrm{pH}$ of 6.19 , dye concentration of $77.1 \mathrm{mg} / \mathrm{L}$ and contact time equal to $6 \mathrm{~h}$. The plots of adsorption isotherm studies are depicted in Fig. 5. The parameters obtained from the two isotherm models are represented in Table 7. According to Table 7, Freundlich isotherm provided better determination coefficient value $\left(R^{2}=0.906\right)$ in comparison with Langmuir isotherm. Based on Table 7 , the value of $1 / n=0.413$ suggests that the Freundlich isotherm is normal. Almost, similar studies were in consistent with the results of the current study. Esmaeli et al. (2013) investigated sorption of AB1 onto brown macroalgae, and they were reported that $A B 1$ adsorption was better described by the Freundlich model (Esmaeli et al. 2013). Also, Hao et al. (2014) studied adsorption of acid dyes by hydroxyl-aluminum pillared bentonite,
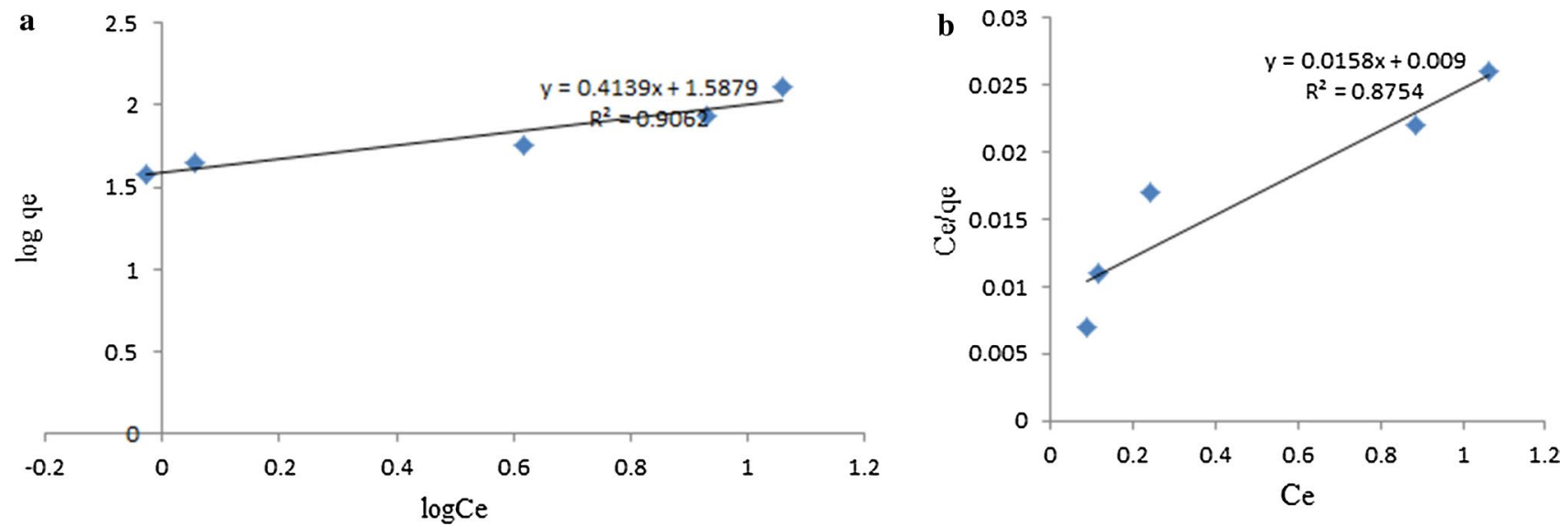

Fig. 5 The plots of Freundlich isotherm (a) and Langmuir isotherm (b) 
Table 7 Result of $\mathrm{AG}_{20}$ adsorption isotherm onto HDTMA-Sep

\begin{tabular}{llc}
\hline Isotherm & Parameter & Value \\
\hline Langmuir & $\mathrm{Q}_{\mathrm{m}}(\mathrm{mg} / \mathrm{g})$ & 63.29 \\
& $\mathrm{~K}_{\mathrm{L}}(\mathrm{L} / \mathrm{mg})$ & 1.75 \\
& $R^{2}$ & 0.875 \\
Freundlich & $1 / n$ & 0.413 \\
& $k_{\mathrm{f}}\left((\mathrm{mg} / \mathrm{g})(\mathrm{L} / \mathrm{mg})^{1 / n}\right)$ & 38.71 \\
& $R^{2}$ & 0.906 \\
\hline
\end{tabular}

and they were reported the Freundlich isotherm as fitted model (Hao et al. 2014).

\section{Interactive effects of parameters}

Result of RSM and the corresponding contour plots as the functions of two parameters ( $\mathrm{pH}$ of solution, dye concentration, contact time and adsorbent dosage) on the adsorption of $\mathrm{AG}_{20}$ onto HDTM-Sep are presented in Fig. 6.

The relationship between adsorbent and dye concentration on the efficiency of the Acid green 20 removal is shown in Fig. 6a. The enhancement of dye removal with increasing adsorbent concentration can be attributed to the fact that increasing amount of adsorbent provides more binding sites (increased surface area) for the adsorption of dye molecules onto the adsorbent, leading to increase in interaction between adsorbent and dye molecules. Hao et al. (2014) prepared hydroxyl-aluminum pillared bentonite, and they were reported that the enhancement of adsorbent dosage leads to increase in the dye removal efficiency (Hao et al. 2014).

The interactive effect of contact time and adsorbent dosage on dye removal is presented in Fig. 6b. It is observed that with increasing contact time and adsorbent dosage, the removal efficiency of dye increased. One of the important parameters that affect wastewater treatment process is contact time (Deniz and Saygideger 2010). Increasing dye removal with increasing contact time can be related to abundant availability of adsorption site for dye molecules, which increase the chance of successful bond of dye molecules onto surface of adsorbent. Özcan et al. (2006) used natural sepiolite as adsorbent for the removal of Acid blue 193 (AB193), and they were reported that amount of AB193 adsorption increased with increasing the contact time (Özcan et al. 2006). Also, Gök et al. (2008) studied adsorption of naphthalene onto organosepiolite, and they were reported similar result (Gök et al. 2008).

The function of $\mathrm{pH}$ of the solution and adsorbent concentration onto adsorption process is shown in Fig. 6c. It is observed that with increasing solution $\mathrm{pH}_{\mathrm{s}}$, the $\mathrm{AG}_{20}$ removal was increased. The enhancement of $A_{20}$ removal can be related to the isoelectric points of the sepiolite $\left(\mathrm{pH}_{\mathrm{IEP}}=6.6\right)\left(\mathrm{Xi}\right.$ et al. 2010a, b). At the $\mathrm{pH}_{\mathrm{IEP}}$, in the
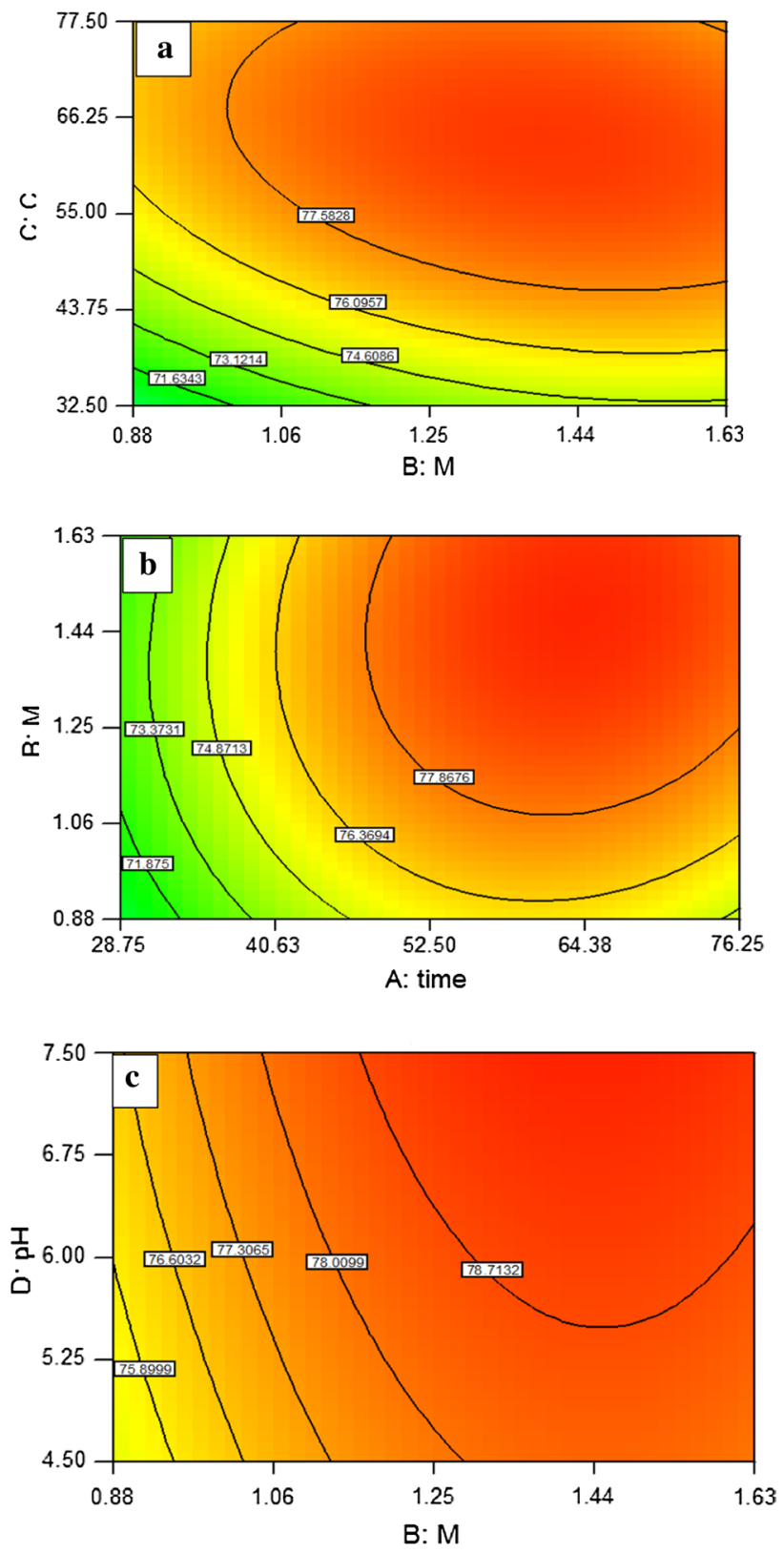

Fig. $62 \mathrm{D}$ counter plots showing the interactive effect of a adsorbent dosage and dye concentration, $\mathbf{b}$ contact time and adsorbent dosage, $\mathbf{c}$ adsorbent dosage and $\mathrm{pH}$

surface of sepiolite, the number of positive and negative charges is equal (Lee and Kim 2002). With the increase in solution $\mathrm{pH}$, the surface of sepiolite is more negatively charged, and electrostatic interaction between $\mathrm{AG}_{20}$ molecules and negatively charged of the sepiolite becomes strong, and thereby, the removal efficiency enhanced. Han et al. (2014) investigated the adsorption of methylene blue (MB) onto natural sepiolite at various $\mathrm{pH}_{\mathrm{s}}$ and found that with increasing $\mathrm{pH}$ of solution, the more $\mathrm{MB}$ is adsorbed (Han et al. 2014). Similar finding has been reported by Qiu 
et al.(2013) in the adsorption of $\mathrm{Sr}$ (II) by sepiolite fibers (Qiu et al. 2013).

\section{$\mathrm{AG}_{20}$ adsorption mechanisms}

The main adsorption mechanisms include chemisorption and physiosorption (Yagub et al. 2014). Chemisorption is characterized by strong intraparticle bonds between an exchange of electrons and molecules. This sorption is stable and irreversible. Physiosorption such as dipole-dipole, hydrogen bonds and $\pi-\pi$ interaction is characterized by weak intraparticle bonds between adsorbent and adsorbate. Physiosorption is deemed to be unstable and reversible sorption (Yagub et al. 2014).

Surfactants with a high degree of hydrophobicity enhanced the adsorption capacity of clays as an effective adsorbent for the removal of organic compounds from aqueous solutions (Jin et al. 2014; Bakhtiary et al. 2013; Oyanedel-Craver et al. 2007). The results of FTIR and XRD indicated that HDTMA cations attached to the surface of sepiolite (not to the internal pores of sepiolite). Thus, HDTMA cations on the surface of sepiolite provided sites for the electrostatic attraction between the positive charge surface of HDTMA-Sep and anionic molecules of $\mathrm{AG}_{20}$. Also, the proposed interaction $\mathrm{AG}_{20}$ adsorption mechanism is the partitioning of the $\mathrm{AG}_{20}$ through hydrophobic bonding of alkyl chains of HDTMA (van der Waals interaction).

The maximum adsorption capacity of $\mathrm{AG}_{20}$ at optimal conditions was achieved 31 and $58 \mathrm{mg} / \mathrm{g}$ for natural sepiolite and modified sepiolite, respectively. It can be said that enhancement of adsorption capacity $(\sim 27$ ( $\mathrm{mg} / \mathrm{g})$ increment) related to the influence of attachment of surfactant cations on the surface of sepiolite. Thus, it can be concluded that the $\mathrm{AG}_{20}$ adsorption mechanisms include both the electrostatic and van der Waals interactions.

\section{Conclusions}

In this study, natural sepiolite was modified with hexadecyltrimethylammonium bromide (HDTMA-Br) to adsorb a textile dye from aqueous solution. An initial dye concentration of $77.1 \mathrm{mg} / \mathrm{L}, \mathrm{pH} 6.19$, adsorbent dosage $1.03 \mathrm{~g} / \mathrm{L}$ and contact time $24.81 \mathrm{~min}$ resulted in the maximum dye removal of $78 \%$ for synthetic solutions, which confirmed by confirmatory experiment. Under this condition, $72 \%$ removal $\mathrm{AG}_{20}$ from real wastewater was achieved. The result of isotherm study showed that the process was best fitted with Freundlich model. The data obtained from kinetic study exhibited that adsorption process can be better described by pseudo-second-order model. The $\mathrm{AG}_{20}$ adsorption mechanisms were electrostatic and van der Waals interactions. The result indicated that contact time and dye concentration have more influence on the removal efficiency rather than $\mathrm{pH}$ and amount of adsorbent. It was proved that modified form of sepiolite is an efficient adsorbent for dye removal from aqueous solution.

Acknowledgements This work was a research project conducted at the Environmental Health Engineering Research Center and was sponsored by the Vice-Chancellor for Research and Technology of Kerman University of Medical Sciences. A note of appreciation is expressed here to the Vice-Chancellor and to all University staff who provided assistance to make this study possible.

Open Access This article is distributed under the terms of the Creative Commons Attribution 4.0 International License (http://creativeco mmons.org/licenses/by/4.0/), which permits unrestricted use, distribution, and reproduction in any medium, provided you give appropriate credit to the original author(s) and the source, provide a link to the Creative Commons license, and indicate if changes were made.

\section{References}

Algoufi Y, Akpan U, Asif M, Hameed B (2014) One-pot synthesis of glycidol from glycerol and dimethyl carbonate over KF/sepiolite catalyst. Appl Catal A Gen 487:181-188

Anari-Anaraki M, Nezamzadeh-Ejhieh A (2015) Modification of an Iranian clinoptilolite nano-particles by hexadecyltrimethyl ammonium cationic surfactant and dithizone for removal of $\mathrm{Pb}$ (II) from aqueous solution. J Colloid Interface Sci 440:272-281

Azizi A, Moghaddam MA, Arami M (2012) Application of wood waste for removal of reactive blue 19 from aqueous solutions: optimization through response surface methodology. Environ Eng Manag J 11:795-804

Bakhtiary S, Shirvani M, Shariatmadari H (2013) Characterization and 2, 4-D adsorption of sepiolite nanofibers modified by N-cetylpyridinium cations. Micropor Mesopor Mat 168:30-36

Bhowmick S, Chakraborty S, Mondal P, Van Renterghem W, Van Den Berghe S, Roman-Ross G, Chatterjee D, Iglesias M (2014) Montmorillonite-supported nanoscale zero-valent iron for removal of arsenic from aqueous solution: kinetics and mechanism. Chem Eng J 243:14-23

Chao H-P, Chen S-H (2012) Adsorption characteristics of both cationic and oxyanionic metal ions on hexadecyltrimethylammonium bromide-modified NaY zeolite. Chem Eng J 193:283-289

Cheng Z, Zhang L, Guo X, Jiang X, Li T (2015) Adsorption behavior of direct red 80 and congo red onto activated carbon/surfactant: process optimization, kinetics and equilibrium. Spectrochim Acta A $137: 1126-1143$

Crini G, Badot P-M (2008) Application of chitosan, a natural aminopolysaccharide, for dye removal from aqueous solutions by adsorption processes using batch studies: a review of recent literature. Prog Pol Sci 33:399-447

Dasgupta J, Singh M, Sikder J, Padarthi V, Chakraborty S, Curcio S (2015) Response surface-optimized removal of Reactive Red 120 dye from its aqueous solutions using polyethyleneimine enhanced ultrafiltration. Ecotox Environ Saf 121:271-278

Deniz F, Saygideger SD (2010) Investigation of adsorption characteristics of Basic Red 46 onto gypsum: equilibrium, kinetic and thermodynamic studies. Desalination 262:161-165

Doğan M, Özdemir Y, Alkan M (2007) Adsorption kinetics and mechanism of cationic methyl violet and methylene blue dyes onto sepiolite. Dyes Pigments 75:701-713 
Dos Santos AB, Cervantes FJ, Van Lier JB (2007) Review paper on current technologies for decolourisation of TEXTILE wastewaters: perspectives for anaerobic biotechnology. Bioresour Technol 98:2369-2385

El Haddad M, Regti A, Laamari MR, Mamouni R, Saffaj N (2014) Use of Fenton reagent as advanced oxidative process for removing textile dyes from aqueous solutions. J Mater Environ Sci 5:667-674

Elwakeel KZ, El-Bindary A, El-Sonbati A, Hawas AR (2017a) Magnetic alginate beads with high basic dye removal potential and excellent regeneration ability. Can J Chem. https://mc06.manus criptcentral.com/cjc-pubs

Elwakeel KZ, Elgarahy AM, Mohammad SH (2017b) Use of beach bivalve shells located at Port Said coast (Egypt) as a green approach for methylene blue removal. J Environ Chem Eng 5:578-587

Esmaeli A, Jokar M, Kousha M, Daneshvar E, Zilouei H, Karimi K (2013) Acidic dye wastewater treatment onto a marine macroalga, Nizamuddina zanardini (Phylum: Ochrophyta). Chem Eng J 217:329-336

Ezechi EH, Bin Mohamed Kutty SR, Malakahmad A, Isa MH (2015) Characterization and optimization of effluent dye removal using a new low cost adsorbent: equilibrium, kinetics and thermodynamic study. Process Safe Environ 98:16-32

Fan Y, Liu H-J, Zhang Y, Chen Y (2015) Adsorption of anionic MO or cationic $\mathrm{MB}$ from $\mathrm{MO} / \mathrm{MB}$ mixture using polyacrylonitrile fiber hydrothermally treated with hyperbranched polyethylenimine. J Hazard Mater 283:321-328

Fu R, Yang Y, Xu Z, Zhang X, Guo X, Bi D (2015) The removal of chromium (VI) and lead (II) from groundwater using sepiolitesupported nanoscale zero-valent iron (S-NZVI). Chemosphere 138:726-734

Gajowiak A, Gładysz-Płaska A, Sternik D, Pikus S, Sabah E, Majdan M (2013) Sorption of uranyl ions on organosepiolite. Chem Eng J 219:459-468

Ghaedi M, Kokhdan SN (2015) Removal of methylene blue from aqueous solution by wood millet carbon optimization using response surface methodology. Spectrochim Acta A 136:141-148

Gök Ö, Özcan AS, Özcan A (2008) Adsorption kinetics of naphthalene onto organo-sepiolite from aqueous solutions. Desalinatio 220:96-107

Han Z-X, Zhu Z, Wu D-D, Wu J, Liu Y-R (2014) Adsorption kinetics and thermodynamics of Acid Blue 25 and methylene blue dye solutions on natural sepiolite. Synth React Inorg Met-Org NanoMet Chem 44:140-147

Hao Y-F, Yan L-G, Yu H-Q, Yang K, Yu S-J, Shan R-R, Du B (2014) Comparative study on adsorption of basic and acid dyes by hydroxy-aluminum pillared bentonite. J Mol Liq 199:202-207

Jin X, Yu B, Chen Z, Arocena JM, Thring RW (2014) Adsorption of Orange II dye in aqueous solution onto surfactant-coated zeolite: characterization, kinetic and thermodynamic studies. J Colloid Interface Sci 435:15-20

Kaboorani A, Riedl B (2015) Surface modification of cellulose nanocrystals $(\mathrm{CNC})$ by a cationic surfactant. Ind Crop Prod 65:45-55

Karimifard S, Moghaddam MRA (2016) Enhancing the adsorption performance of carbon nanotubes with a multistep functionalization method: optimization of Reactive Blue 19 removal through response surface methodology. Process Safe Environ 99:20-29

Kumar M, Tamilarasan R (2013) Modeling studies for the removal of methylene blue from aqueous solution using Acacia fumosa seed shell activated carbon. J Environ Chem Eng 1:1108-1116

Lazarević S, Janković-Častvan I, Jovanović D, Milonjić S, Janaćković $\mathrm{D}$, Petrović $\mathrm{R}$ (2007) Adsorption of $\mathrm{Pb}^{2+}, \mathrm{Cd}^{2+}$ and $\mathrm{Sr}^{2+}$ ions onto natural and acid-activated sepiolites. Appl Clay Sci 37:47-57

Lazarević S, Janković-Častvan I, Potkonjak B, Janaćković D, Petrović $\mathrm{R}$ (2012) Removal of $\mathrm{Co}^{2+}$ ions from aqueous solutions using iron-functionalized sepiolite. Chem Eng Process Process Intensif 55:40-47

Lee SY, Kim SJ (2002) Expansion of smectite by hexadecyltrimethylammonium. Clays Clay Miner 50:435-445

Lescano L, Castillo L, Marfil S, Barbosa S, Maiza P (2014) Alternative methodologies for sepiolite defibering. Appl Clay Sci 95:378-382

Li Z, Bowman RS (1997) Counterion effects on the sorption of cationic surfactant and chromate on natural clinoptilolite. Environ Sci Technol 31:2407-2412

Li Z, Bowman RS (2001) Retention of inorganic oxyanions by organo-kaolinite. Water Res 35:3771-3776

Li H, Li Y, Xiang L, Huang Q, Qiu J, Zhang H, Sivaiah MV, Baron F, Barrault J, Petit S (2015) Heterogeneous photo-Fenton decolorization of Orange II over Al-pillared Fe-smectite: response surface approach, degradation pathway, and toxicity evaluation. J Hazard Mater 287:32-41

Li X, Zhao Y, Xi B, Mao X, Gong B, Li R, Peng X, Liu H (2016) Removal of nitrobenzene by immobilized nanoscale zero-valent iron: effect of clay support and efficiency optimization. Appl Surf Sci 370:260-269

Liu S, Ding Y, Li P, Diao K, Tan X, Lei F, Zhan Y, Li Q, Huang B, Huang Z (2014) Adsorption of the anionic dye Congo red from aqueous solution onto natural zeolites modified with $N, N$ dimethyl dehydroabietylamine oxide. Chem Eng J 248:135-144

Madejová J (2003) FTIR techniques in clay mineral studies. Vib Spectrosc 31:1-10

Malakootian M (2016) Performance evaluation of photo-fenton process in removal of Acid green 20 dye from wastewater of textile industries. J Rafsanjan Univ Med Sci 14:827-840

Malakootian M, Ranandeh Kalankesh L, Loloi M (2013) Efficiency of hybrid nano particles of $\mathrm{TiO}_{2} / \mathrm{SiO}_{2}$ in removal of lead from paint industry effluents. J Mazandaran Univ Med Sci 23:244-254

Malakootian M, Mansoorian HJ, Hosseini A, Khanjani N (2015) Evaluating the efficacy of alumina/carbon nanotube hybrid adsorbents in removing Azo Reactive Red 198 and Blue 19 dyes from aqueous solutions. Process Safe Environ 96:125-137

Malakootian M, Asadipour A, Mohammadi SS (2016) A survey of the efficacy of calcium peroxide nanoparticles in the removal of reactive Red 198 from textile wastewater. J Sabzevar Univ Med Sci 23:110-121

Malakootian M, Daneshkhah M, Hossaini H (2017) Removal of phosphates from aqueous solution by sepiolite-nano zero valent iron composite optimization with response surface methodology. Int J Environ Sci Technol. https://doi.org/10.1007/s13762-017-1520-y

Mall ID, Srivastava VC, Agarwal NK (2006) Removal of Orange-G and Methyl Violet dyes by adsorption onto bagasse fly ashkinetic study and equilibrium isotherm analyses. Dyes Pigments 69:210-223

Mandal S, Mahapatra S, Patel R (2015) Enhanced removal of Cr(VI) by cerium oxide polyaniline composite: optimization and modeling approach using response surface methodology and artificial neural networks. J Environ Chem Eng 3:870-885

Marjanović V, Lazarević S, Janković-Častvan I, Jokić B, Janaćković D, Petrović R (2013) Adsorption of chromium (VI) from aqueous solutions onto amine-functionalized natural and acid-activated sepiolites. Appl Clay Sci 80:202-210

Olya M, Vafaee M, Jahangiri M (2015) Modeling of acid dye decolorization by $\mathrm{TiO} 2-\mathrm{Ag} 2 \mathrm{O}$ nano-photocatalytic process using response surface methodology. J Saudi Chem Soc 21:633-642

Oyanedel-Craver VA, Fuller M, Smith JA (2007) Simultaneous sorption of benzene and heavy metals onto two organoclays. J Colloid Interface Sci 309:485-492

Özcan AS, Gök Ö (2012) Structural characterization of dodecyltrimethylammonium (DTMA) bromide modified sepiolite and its adsorption isotherm studies. J Mol Struct 1007:36-44

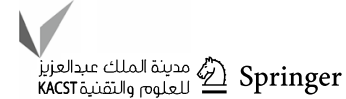


Özcan AS, Erdem B, Özcan A (2004) Adsorption of Acid Blue 193 from aqueous solutions onto Na-bentonite and DTMA-bentonite. J Colloid Interface Sci 280:44-54

Özcan A, Öncu EM, Özcan AS (2006) Kinetics, isotherm and thermodynamic studies of adsorption of Acid Blue 193 from aqueous solutions onto natural sepiolite. Colloids Surfaces A 277:90-97

Qiu Y, Yu S, Song Y, Wang Q, Zhong S, Tian W (2013) Investigation of solution chemistry effects on sorption behavior of $\mathrm{Sr}$ (II) on sepiolite fibers. J Mol Liq 180:244-251

Rožić M, Miljanić S (2011) Sorption of HDTMA cations on Croatian natural mordenite tuff. J Hazard Mater 185:423-429

Sharifipour F, Hojati S, Landi A, Faz CA (2015) Removal of lead from aqueous solutions using Iranian natural sepiolite: effects of contact time, temperature, $\mathrm{Ph}$, dose and heat-pretreatments. Irrig Sci Eng (JISE) 38:135-147

Shirsath SR, Patil AP, Patil R, Naik JB, Gogate PR, Sonawane SH (2013) Removal of Brilliant Green from wastewater using conventional and ultrasonically prepared poly (acrylic acid) hydrogel loaded with kaolin clay: a comparative study. Ultrason Sonochem 20:914-923

Srivastava V, Sharma Y, Sillanpää M (2015) Response surface methodological approach for the optimization of adsorption process in the removal of $\mathrm{Cr}(\mathrm{VI})$ ions by $\mathrm{Cu}_{2}(\mathrm{OH})_{2} \mathrm{CO}_{3}$ nanoparticles. Appl Surf Sci 326:257-270

Subramaniam R, Ponnusamy SK (2015) Novel adsorbent from agricultural waste (cashew NUT shell) for methylene blue dye removal: optimization by response surface methodology. Water Resour Ind 11:64-70

Tahir S, Rauf N (2006) Removal of a cationic dye from aqueous solutions by adsorption onto bentonite clay. Chemosphere 63:1842-1848

Tee H-C, Lim P-E, Seng C-E, Nawi MAM, Adnan R (2015) Enhancement of azo dye Acid Orange 7 removal in newly developed horizontal subsurface-flow constructed wetland. J Environ Manag 147:349-355

Thiam A, Sires I, Garrido JA, Rodríguez RM, Brillas E (2015) Effect of anions on electrochemical degradation of azo dye Carmoisine (Acid Red 14) using a BDD anode and air-diffusion cathode. Separ Purif Techno J 140:43-52

Üzum Ç, Shahwan T, Eroğlu AE, Hallam KR, Scott TB, Lieberwirth I (2009) Synthesis and characterization of kaolinite-supported zerovalent iron nanoparticles and their application for the removal of aqueous $\mathrm{Cu}^{2+}$ and $\mathrm{Co}^{2+}$ ions. Appl Clay Sci 43:172-181

Wang C-C, Juang L-C, Hsu T-C, Lee C-K, Lee J-F, Huang F-C (2004) Adsorption of basic dyes onto montmorillonite. J Colloid Interface Sci 273:80-86

Wang J, Ren S, Guo M (2012) Preparation and humidity controlling behaviors of sepiolite/polyacrylic acid (sodium) composite. Proc Eng 27:423-430

Wang M-X, Zhang Q-L, Yao S-J (2015a) A novel biosorbent formed of marine-derived Penicillium janthinellum mycelial pellets for removing dyes from dye-containing wastewater. Chem Eng J 259:837-844

Wang W, Zhang H, Zhang L, Wan H, Zheng S, Xu Z (2015b) Adsorptive removal of phosphate by magnetic $\mathrm{Fe}_{3} \mathrm{O}_{4} @ \mathrm{C} @ \mathrm{ZrO}_{2}$. Colloid Surfaces A 469:100-106
Xi Y, Mallavarapu M, Naidu R (2010a) Adsorption of the herbicide 2, 4-D on organo-palygorskite. Appl Clay Sci 49:255-261

Xi Y, Mallavarapu M, Naidu R (2010b) Preparation, characterization of surfactants modified clay minerals and nitrate adsorption. Appl Clay Sci 48:92-96

Xu S, Boyd SA (1995) Alternative model for cationic surfactant adsorption by layer silicates. Environ Sci Technol 29:3022-3028

Yagub MT, Sen TK, Afroze S, Ang HM (2014) Dye and its removal from aqueous solution by adsorption: a review. Adv Colloid Interfac 209:172-184

Ye J, Cong X, Zhang P, Zeng G, Hoffmann E, Liu Y, Wu Y, Zhang H, Fang W, Hahn HH (2016) Application of acid-activated Bauxsol for wastewater treatment with high phosphate concentration: characterization, adsorption optimization, and desorption behaviors. $\mathrm{J}$ Environ Manag 167:1-7

Yin H, Yun Y, Zhang Y, Fan C (2011) Phosphate removal from wastewaters by a naturally occurring, calcium-rich sepiolite. J Hazard Mater 198:362-369

Yolmeh M, Najafi MBH, Farhoosh R (2014) Optimisation of ultrasound-assisted extraction of natural pigment from annatto seeds by response surface methodology (RSM). Food Chem 155:319-324

Zhang Z, Zheng H (2009) Optimization for decolorization of azo dye acid green 20 by ultrasound and $\mathrm{H} 2 \mathrm{O} 2$ using response surface methodology. J Hazard Mater 172:1388-1393

Zhang Y-R, Su P, Huang J, Wang Q-R, Zhao B-X (2015) A magnetic nanomaterial modified with poly-lysine for efficient removal of anionic dyes from water. Chem Eng J 262:313-318

Zheng L, Wang C, Shu Y, Yan X, Li L (2015) Utilization of diatomite/ chitosan-Fe(III) composite for the removal of anionic azo dyes from wastewater: equilibrium, kinetics and thermodynamics. Colloid Surface A 468:129-139

Zhou X-J, Guo W-Q, Yang S-S, Ren N-Q (2012) A rapid and low energy consumption method to decolorize the high concentration triphenylmethane dye wastewater: operational parameters optimization for the ultrasonic-assisted ozone oxidation process. Bioresource Technol 105:40-47

Zhu Y, Zhu Z, Chen Y, Yang F, Qin H, Xie L (2013) Kinetics and thermodynamics of sorption for as $(\mathrm{V})$ on the porous biomorphgenetic composite of $\alpha-\mathrm{Fe}_{2} \mathrm{O}_{3} / \mathrm{Fe}_{3} \mathrm{O}_{4} / \mathrm{C}$ with eucalyptus wood hierarchical microstructure. Water Air Soil Poll 224:1589

Zinatizadeh A, Mohamed A, Abdullah A, Mashitah M, Isa MH, Najafpour G (2006) Process modeling and analysis of palm oil mill effluent treatment in an up-flow anaerobic sludge fixed film bioreactor using response surface methodology (RSM). Water Res 40:3193-3208

Publisher's Note Springer Nature remains neutral with regard to jurisdictional claims in published maps and institutional affiliations. 